\title{
Cervical Sympathectomy for Cerebral Vasospasm after Aneurysm Rupture
}

\author{
Jiro SuzukI, Takashi Iwabuchı* and Shigeaki HorI \\ Division of Neurosurgery, Institute of Brain Diseases, \\ Tohoku University School of Medicine, Sendai, Japant
}

\begin{abstract}
Summary
The authors report a series of 11 cases of ruptured intracranial aneurysms followed by cerebral vasospasm manifesting neurological deficits. These patients were treated by cervical sympathectomy consisting of perivascular sympathectomy of the cervical internal carotid artery and superior cervical ganglionectomy on the same side as the cerebral angiospasm. Improvement of symptoms was observed following 13 procedures in 11 patients, within 10 hours in four cases, on the next day in five cases, and by the seventh day in two cases. In the remaining two cases no beneficial effect was observed. This technique was most valuable when it was done immediately after the appearance of the symptoms of infarction, before the development of irreversible brain damage.
\end{abstract}

Key words: aneurysm rupture, cerebral infarction, sympathectomy, ganglionectomy, vasospasm

\section{Introduction}

Cerebral vasospasm is observed angiographically as well as under direct vision on craniotomy in such conditions as head injury, intracranial inflammatory disease, and subarachoid hemorrhage. ${ }^{4,7,8,12,14,16,31,39,41,51)}$. This phenomenon might be nature's defensive mechanism to prevent fatal bleeding from ruptured aneurysms. However, it may sometimes induce cerebral infarction characterized by paralysis, aphasia, and disturbances of consciousness.

In such cases the neurological deficits often cannot be controlled with vasodilators or other supportive medical cares. Thus the establishment of a clinical procedure for the management of cerebral vasospasm is one of the most urgent problems in practical neurosurgery.

There are many opinions as to the innervation of human cerebral arteries. ${ }^{11,13.25 .35 .50 .53)}$ The electron-microscopic study by Sato and Suzuki $^{38}$ ) indentified numbers of myelinated nerves in the wall of human cerebral arteries, where vasospasm is commonly seen. In addition, degeneration of the adrenergic nerve elements in the ipsilateral cerebral arteries has been electron-microscopically demonstrated 28 to 48 hours after unilateral superior cervical ganglionectomy in animals. ${ }^{17.37)}$

*Present address: Department of Neurosurgery, Hirosaki University School of Medicine, Hirosaki, Japan.
On the basis of these data, cervical sympathectomy was performed in 11 cases with ruptured aneurysm, symptoms of severe cerebral infarction and intracranial vasospasm demonstrated on carotid angiograms.

\section{Technique}

Perivascular sympathectomy of the cervical internal carotid artery associated with superior cervical ganglionectomy (Fig. 1) was carried out on the same side as the intracranial vasospasm. A skin incision should be made, avoiding a likely tracheostomy site when required. The internal jugular vein was retracted anterolaterally and perivascular denervation was performed starting $1 \mathrm{~cm}$ proximal to the carotid bifurcation and extending to the internal carotid as distal as possible, and including the beginning of the external carotid and the carotid body.
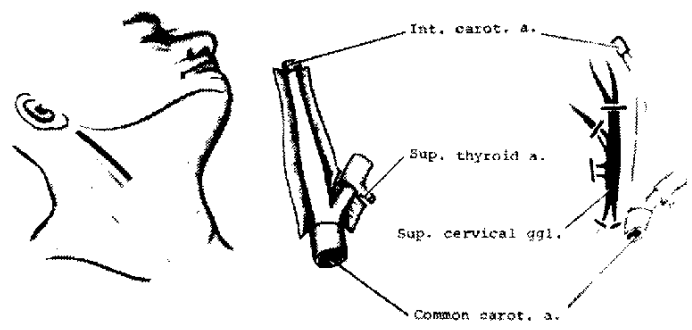

Fig. 1. Schematic illustration of a right cervical sympathectomy, showing the skin incision (left), pericarotid sympathectomy (center), and superior cervical ganglionectomy (right). 

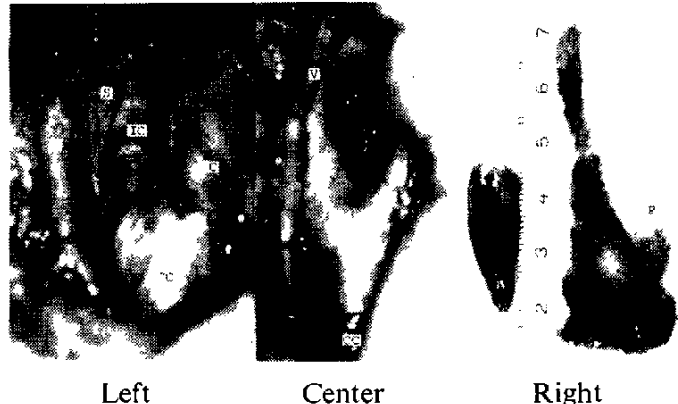

Right

Fig. 2. Intraoperative photographs of the right cervical sympathectomy (left) and pericarotid sympathectomy (center). Rt. vagus nerve (V), superior cervical ganglion (S), internal, external and common carotid arteries (IC, EC, CC). Right: The excised rt. superior cervical ganglion on the left, and pericarotid sympathetic plexus (P).

The superior cervical ganglion was excised completely as far as possible (Fig. 2). When this procedure was planned on both sides at once, anesthetic block of the nerve element was attempted prior to its excision for examination of a possible untoward effect on cardiopulmonary function.

\section{Case Reports}

Some illustrative cases are given in detail.

\section{Case I}

On August 10, 1971, this 61-year-old woman felt a girdling pain in the occipital and neck region, followed by vertigo, blurred vision, weakness of the right leg and frequent vomiting. These symptoms disappeared on the next day. A spinal tap on August 31 revealed bloody cerebrospinal fluid (CSF); carotid angiograms demonstrated aneurysms of the right and left middle cerebral arteries. Cerebral vasospasm was not observed at this time (Fig. 3 upper $l e f t$ ). On October 1, a ligature and a clip were successfully placed on the aneurysmal stalk bilaterally under hypothermic anesthesia at $27^{\circ} \mathrm{C}$. The right and left middle cerebral aneurysms measured $6 \times 5 \times 5 \mathrm{~mm}$ and $3 \times 3 \times 4 \mathrm{~mm}$ respectively. A hematoma of $30 \mathrm{ml}$ was also evacuated from the right Sylvian fissure.

Immediately after the direct aneurysm surgery, there was no neurological deficit nor disturbance of consciousness. However, the next day she suffered from left hemiparesis, and vasospasm of the beginning portion of the right

middle cerebral artery was revealed angiographically (Fig. 3 upper right). This symptom of cerebral infarction persisted for 17 days despite several supportive treatments with $20 \%$ mannitol solution, low molecular dextran, vasodilators, and stellate ganglion block.

On October 19, right cervical sympathectomy was carried out. On the next day, the motor paresis improved; angiospasm diminished on carotid angiogram (Fig. 3 lower left). Eight days later, the patient was discharged in good mental and physical conditions except for a right Horner's sign.

\section{Case 2}

On September 28, 1971, this 52-year-old woman had a severe bursting headache and lost consciousness for six hours. On examination, bloody CSF and an anterior communicating aneurysm were found (Fig. 4 upper left). The only neurological abnormality was neck stiffness.

On October 2, the aneurysm stalk was ligated through a bifrontal craniotomy under hypothermic anesthesia at $25.5^{\circ} \mathrm{C}$. At craniotomy, arteriosclerosis and a hypoplastic horizontal portion of the right anterior cerebral artery were revealed; the aneurysm was irregular in shape and $10 \times 8 \times 8 \mathrm{~mm}$ to $2 \times 3 \times 2 \mathrm{~mm}$ in size. Postoperatively no neurological deficit was observed except for neck stiffness; however, the patient became aggressive, with illogical speech and pathological reflexes on the right side, and six days after aneurysm surgery she became completely aphasic. Left carotid angiography revealed diffuse vasospasm of the terminal portion of the internal carotid, anterior and middle cerebral arteries. Thalamic perforating branches were not visible at angiography (Fig. 4 upper right). A slight transient improvement of symptoms was observed, but she became hemiplegic. Stellate ganglion block caused only temporary improvement, and supportive treatment with vasodilator and low molecular dextran solution was not effective. On October 30 , continuous ventricular drainage was instituted and left cervical sympathectomy performed. Seven hours after these procedures, the patient spoke several words logically and began to recover from the cerebral infarction. Angiograppy showed improvement of the vasospasm (Fig. 4 lower right). 


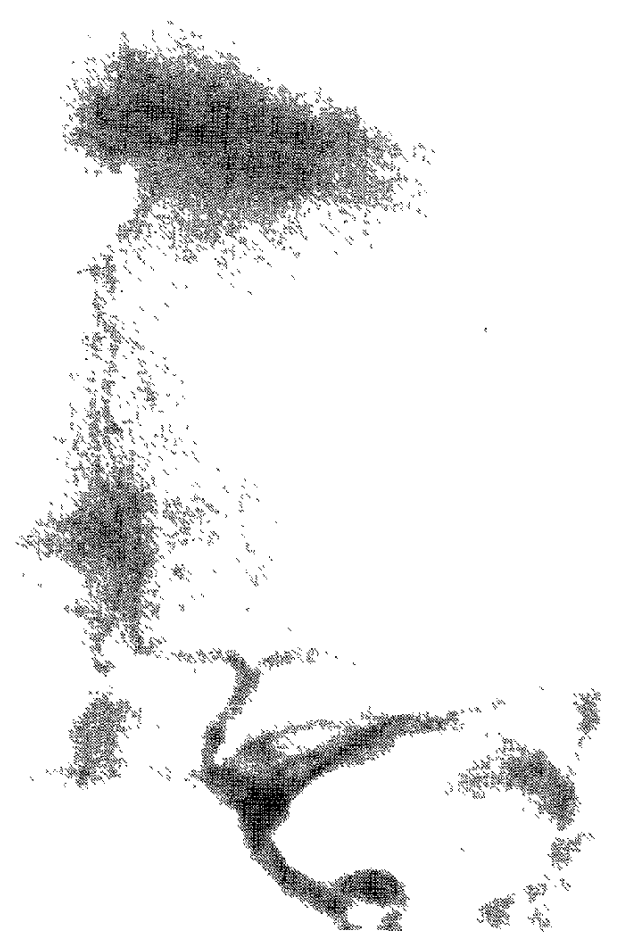

Upper Left

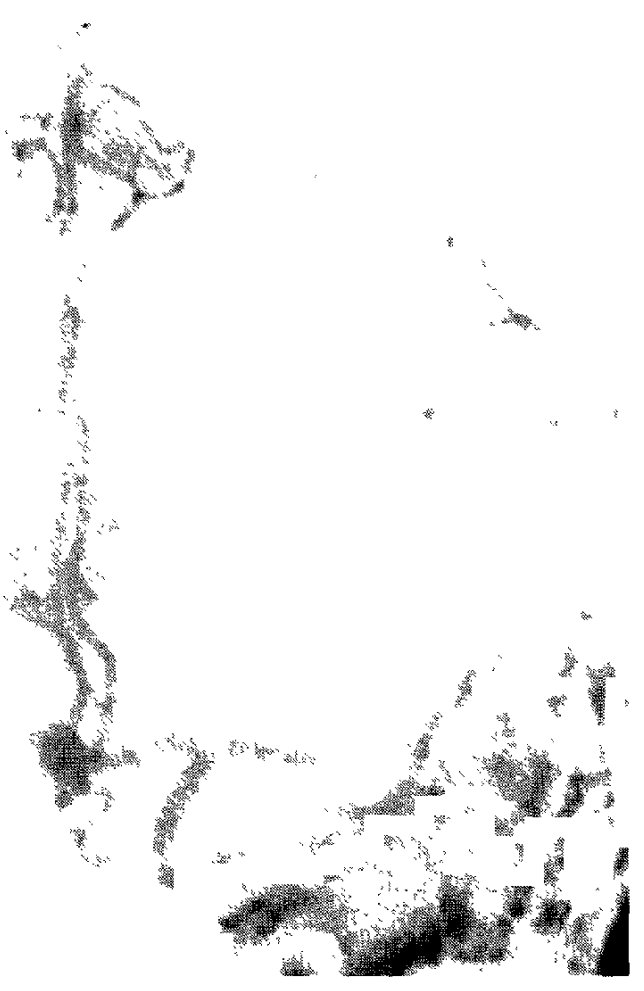

Upper Right

Fig. 3. Case 1. Right carotid angiograms, lateral view. Upper Left: 44 days after aneurysm rupture. An aneurysm can be seen on the trifurcation of the right middle cerebral artery (arrow), with no vasospasm. Upper Right: Thirteen days after aneurysm stalk was successfully clipped. Right anterior and middle cerebral arteries and $\mathrm{C}_{1}$ portion are noticeably spastic. Lower Left: Two days after the right cervical sympathectomy the spasm is diminishing. 


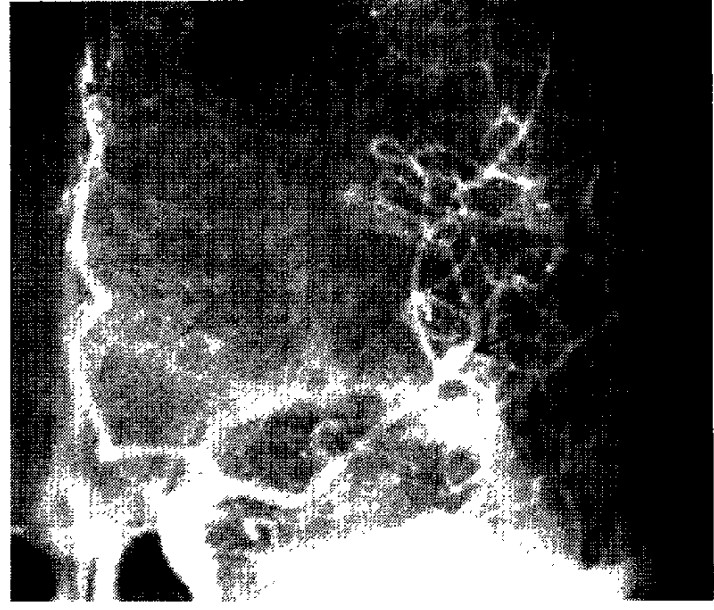

Upper Left

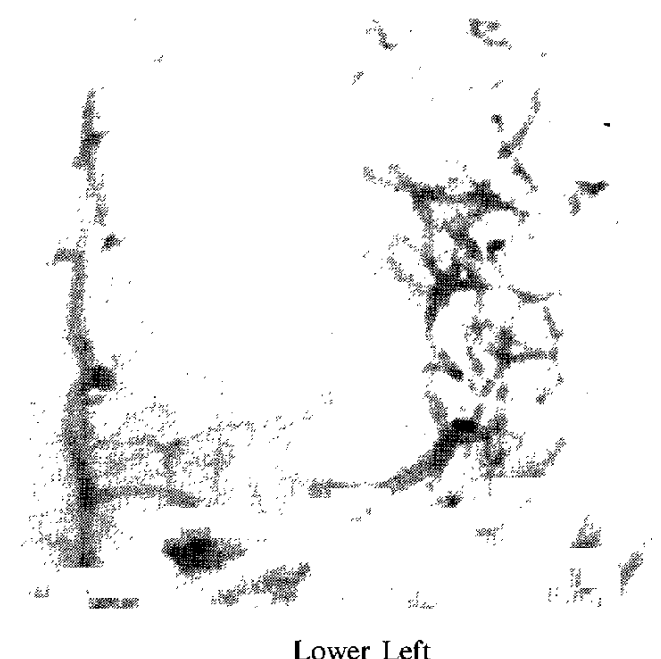

Lower Left

\section{Case 4}

On October 24, 1971, this 48-year-old woman suffered from a severe diffuse headache, nausea, and vertigo, She was admitted three days later with a dull headache, a stiff neck, and in a delirious state. Examination revealed bloody CSF and a left middle cerebral aneurysm was demonstrated at angiograppy (Fig. 5 upper left). Nine days after admission, the patient began to speak illogically, and right hemiplegia was noted. The left carotid angiogram demonstrated marked vasospasm on the carotid fork (Fig. 5 upper right).

Continuous ventricular drainage was instituted and several hours later her speech and consciousness returned to nearly normal. Headache, neck stiffness, right hemiparesis, and papilledema were still noted. On October 31,

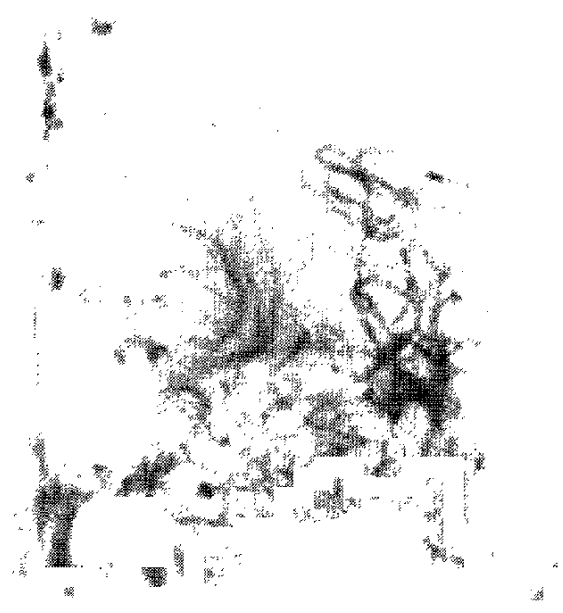

Upper Right

Fig. 4. Case 2. Left carotid angiograms, anteroposterior view. Upper Left: Three days after the aneurysm rupture. The anterior communicating aneurysm can be seen with no vasospasm. Upper Right: Six days after the direct aneurysm surgery. The aneurysm has disappeared completely. Insufficient filling due to vasospasm of the carotid fork, anterior and middle cerebral arteries and thalamic perforating branches are noted. Lower Left: Six days after ventricular drainage and the left cervical sympathectomy. The vasospasm is diminished. Note also the improved visualization of the thalamic perforating branches.

the patient became semicomatose despite patent and operating ventricular drainage. In spite of her desperate condition, ${ }^{45,46)}$ she was subjected to left frontal craniotomy followed by left cervical sympathectomy under normothermic anesthesia. An aneurysm measuring $5 \times 4 \times 4$ $\mathrm{mm}$ was clipped and a Sylvian fissure hematoma of $50 \mathrm{gm}$ was evacuated. The next day, her consciousness improved and left carotid angiography showed abatement of the vasospasm. On the third postoperative day, she became alert and her motor paresis had disappeared. On November 12, vasospasm was no longer visible on the carotid angiogram (Fig. 5 lower left). She was discharged two weeks later in a very good condition except for a left Horner's sign. 


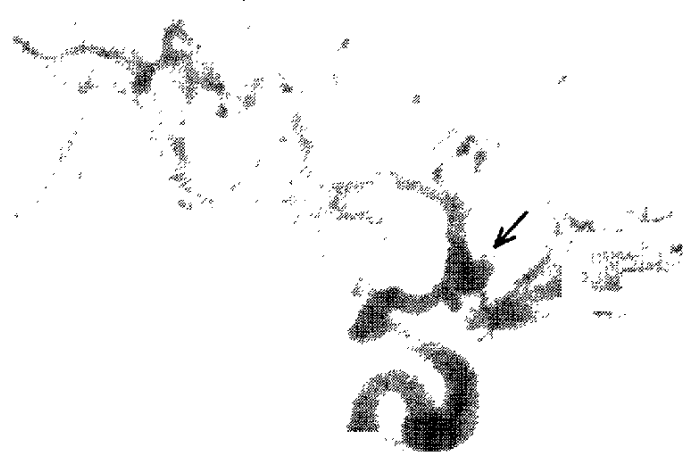

Upper Left

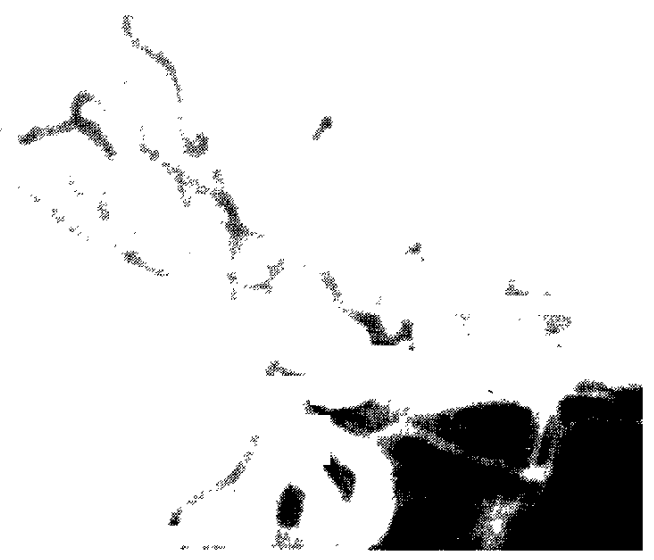

Lower Left

On February 27, 1972, this 62-year-old woman suddenly groaned, vomited, and $1 \frac{1}{2}$ hours later became semicomatose. The systemic blood pressure was $220 / 120 \mathrm{~mm} \mathrm{Hg}$. Examination on the following day showed neck stiffness. An anterior communicating aneurysm was demonstrated on carotid angiography. Bloody CSF with a pressure of $250 \mathrm{~mm} \mathrm{H}_{2} \mathrm{O}$ was noted on ventricular tapping, and continuous drainage was instituted. Two days later she was alert and well oriented.

On March 3, the aneurysmal stalk was successfully clipped and ligated under hypothermic anesthesia at $27.5^{\circ} \mathrm{C}$. The right $A_{1}$ portion was very hypoplastic. Left cervical sympathectomy was also performed as a precaution against postoperative vasospasm. The day after surgery, the patient had no motor disturbance. On March 6, she became drowsy, with weakness of the left arm; the left $A_{1}$ portion appeared spas-

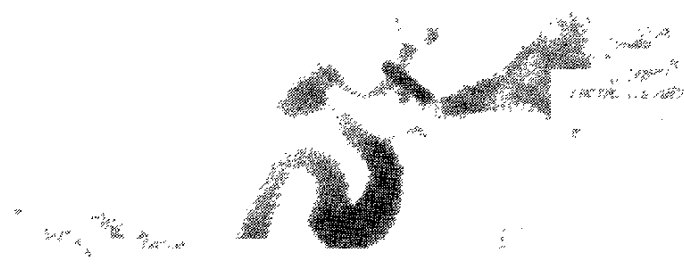

Upper Right

Fig. 5. Case 4. Left carotid angiograms, anteroposterior view. Upper Left: Three days after the aneurysm rupture, showing the left middle cerebral trifurcation aneurysm (arrow), with no vasospasm. Upper Right: Eight days postrupture. Diffuse vasospastic narrowing of the anterior cerebral artery and carotid fork is seen; a portion of $\mathrm{M}_{1}$ has been replaced with a collateral network. Upper Left: Complete disappearance of the vasospasm is shown 12 days after the left cervical sympathectomy. The arterial segments and the thalamic perforating branches are well visualized.

tic on angiography. Right cervical sympathectomy was carried out. Ten hours after this procedure, her consciousness seemed to have improved a little but the next day she was semicomatose and she died on March 9. At autopsy, marked brain swelling due to scattered infarction and softening in bilateral cerebral hemispheres were observed.

\section{Case 10}

On June 6, 1972, this 43-year-old woman suddenly vomited, and became unconscious for several hours. On the next day she was admitted to the hospital; bloody CSF was found at spinal tap. A left internal carotid-posterior communicating aneurysm was revealed on carotid angiograms. On June 21 , she had a generalized tonic convulsion, resulting in right-sided hemiparesis and semicoma. At lumbar puncture, the CSF was clear; left carotid angiography revealed vasospasm with diffuse irregular narrowing at 
the carotid fork and peripheral segments. Left cervical sympathectomy and tracheostomy were performed as emergency procedures. The next day her consciousness slightly improved but again deteriorated and she died on June 28 . 1972. Autopsy revealed diffuse basal subarachnoid hemorrhage and marked swelling of the left hemisphere. The left internal carotidposterior communicating gneurysm measured $7 \times 5 \times 5 \mathrm{~mm}$. On the cut surface infarction was noted at the left pallidum and parietooccipital cortices.

\section{Case 11}

This 36-year-old woman was admitted on October 2, 1972, three days after a subarachnoid hemorrhagc. Right carotid angiograms taken four days after the hrmorrhage revealed an aneurysm at the junction of the internal carotid and posterior communicating arteries, with vasospasm around the carotid fork (Fig. 6 upper (eft). She had been alert and had had no neurological signs except for moderate meningeal irritation until seven days after the hemorrhage when she became drowsy and developed progressive left hemiparesis. Right carotid angiograppy was repeated and showed more pronounced vasospasm in the same arteries than before (Fig. 6 upper right). Immediately after angiography the neck of the aneurysm was clipped, continuous ventricular drainage was instituted, and sympathectomy on the right side was carried out. Within six hours postoperatively the patient became alert and her hemiplegia improved markedly. On the third postoperative day she was no longer hemiplegic, and improvement of the vasospasm was noted on the angiograms (Fig. 6 lower left). She was discharged 14 days after the surgery without any neurological deficit except for right Horner's sign. Right carotid angiograms taken three months later showed entirely normal cerebral arteries (Fig. 6 lower right).

\section{Summary of Cases}

This series includes 11 cases operated on between September 1971 and October 1972. In two patients the procedures were bilateral. Clinical data are presented in Table 1 . The interval between rupture of the aneurysm and cervical sympathectomy varied from five to 70

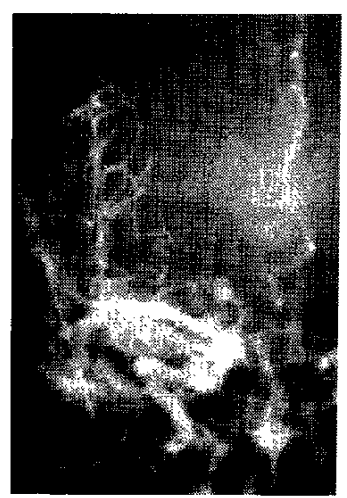

Upper Left

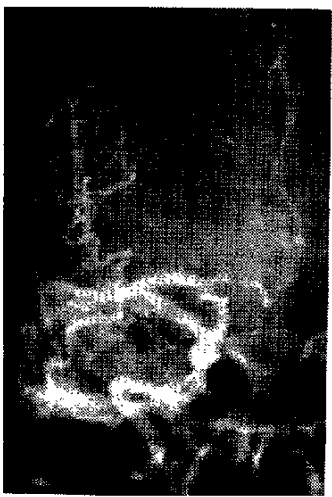

Lower Left

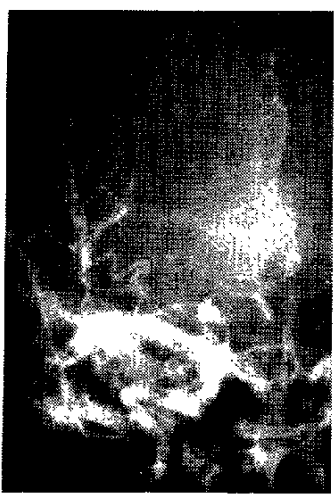

Upper Right

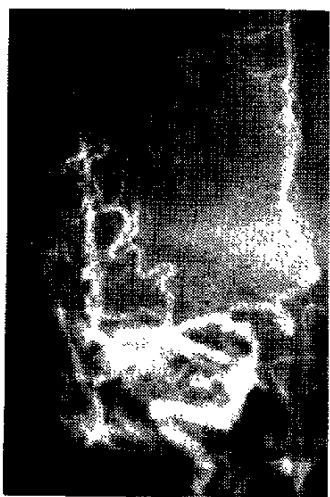

Lower Right
Fig. 6. Case 11. Right carotid angiograms, anteroposterior view. Upper Left: Five days after subarachnoid hemorrhage. An aneurysm is visualized at the junction of the internal carotid and posterior communicating arteries, with vasospasm in the carotid fork. Upper Right: Seven days after the hemorrhage when the patient became drowsy and hemiplegic. There is now pronounced vasospasm. Lower Left: Three days after the clipping of the aneurysm neck and cervical sympathectomy. $\mathrm{C}_{1}$ and $A_{1}$ are less spastic and $M_{1}$ is rather dilated. Lower Right: Three months after surgery. The cerebral arteries now have an entirely normal appearance.

days. Symptoms of cerebral infarction as well as carotid angiographic evidence of vasospasm were observed prior to aneurysm surgery in Cases $4,5,6,10$, and 11 . Of the cases in which symptoms of cerebral infarction appeared after the aneurysm surgery, all but one were alert; Case 3 was semicomatose. Ventricular drainage was performed in nine cases. In every case, symptoms of cerebral infarction due to vasospasm appeared three days or more after the rupture of the aneurysm.

In the cases where cerebral infarction appeared postoperatively, the vasospasm might 


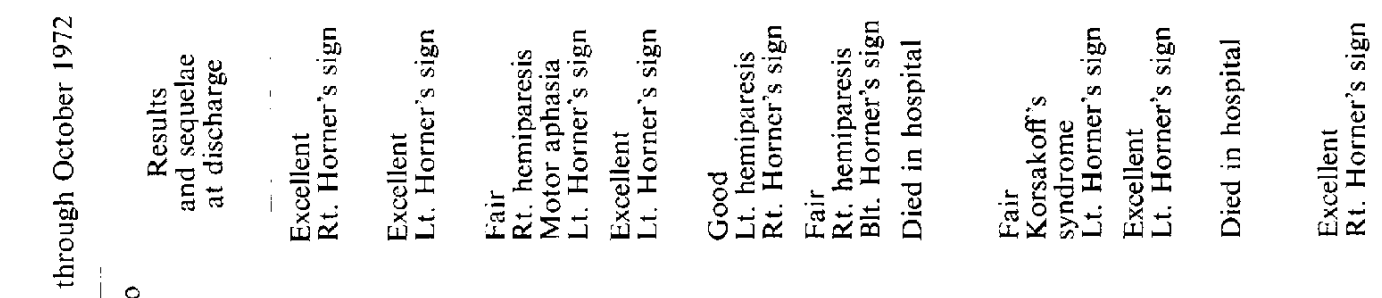

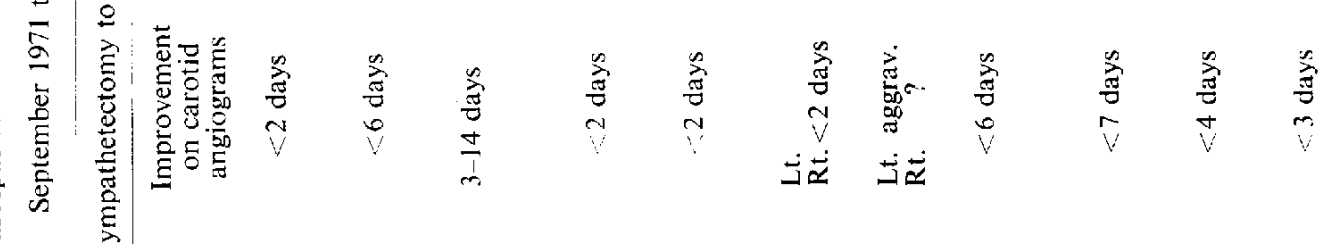

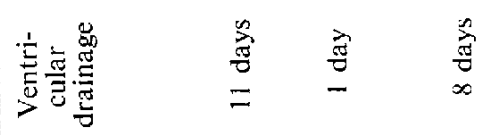

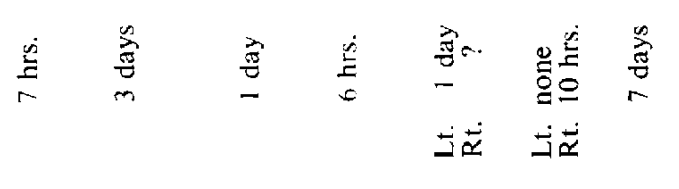

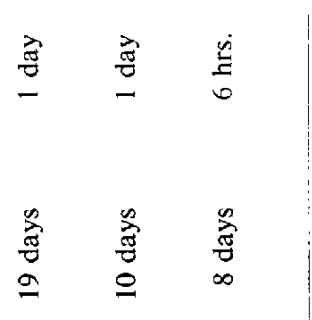

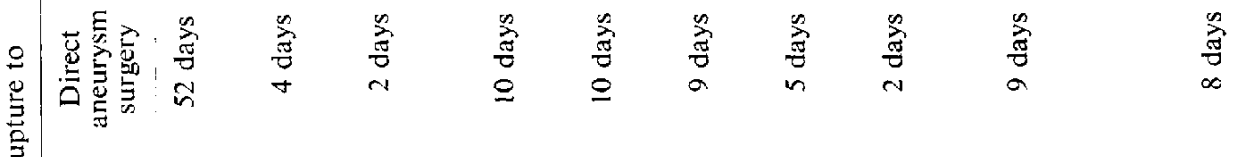

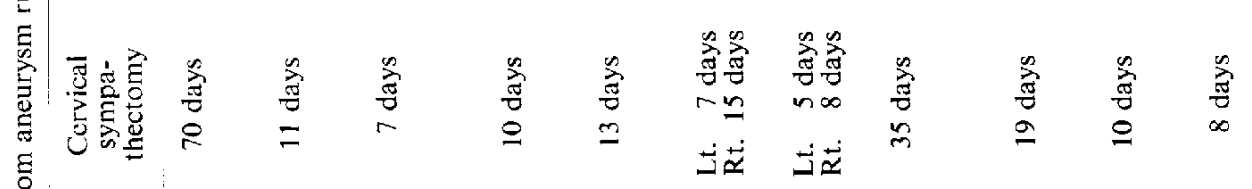

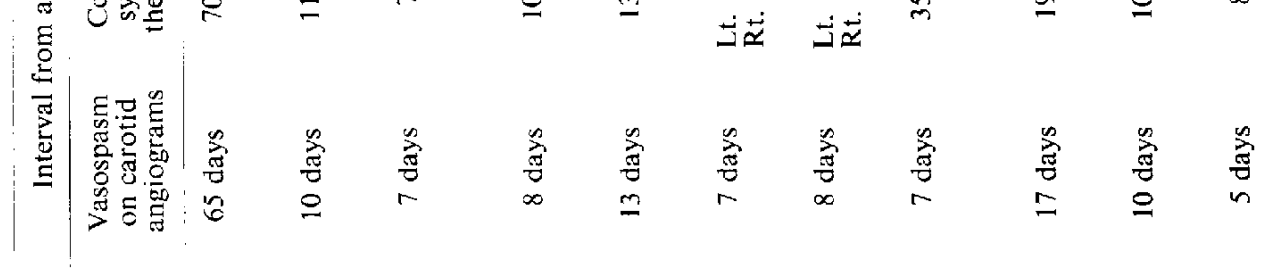

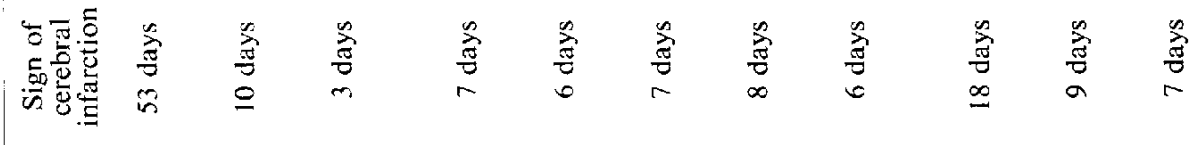

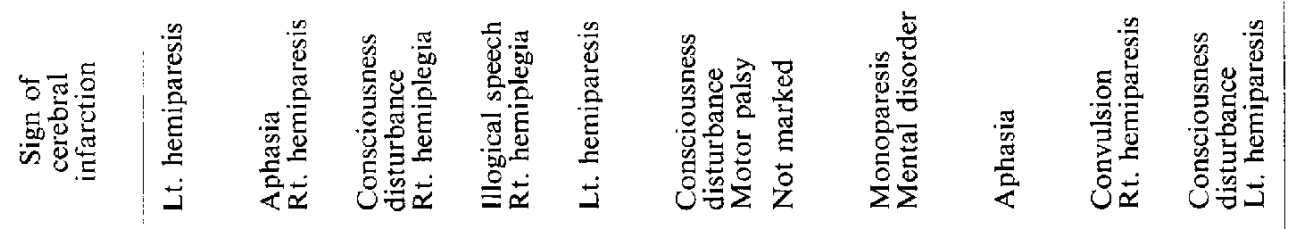

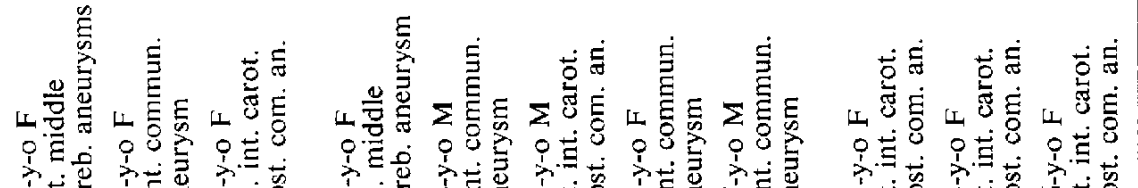

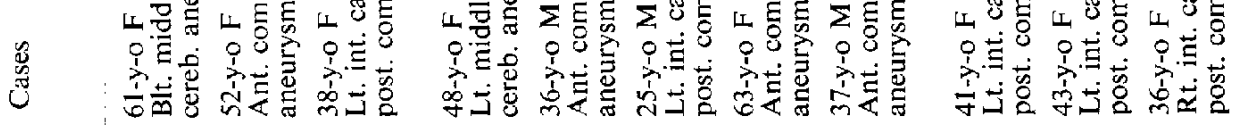


have been caused by mechanical stimulation of the arterial wall, ${ }^{5.18}$ ) intracranial bleeding, ${ }^{44)}$ or the introduction of a so-called angiospasmogenic substance. ${ }^{7,19,20,36)}$ In Case 7 there was generalized cerebral arteriosclerosis, and prophylactic cervical sympathectomy was performed on the side of the dominant $A_{1}$ segment of the anterior cerebral artery; nevertheless the patient suffered from cerebral vasospasm leading to fatal cerebral infarction. Case 10 had an extremely sever infarction in one of the thalamic perforating branches manifested by convulsion. The sympathectomy should have been done immediately instead of six hours after the onset of infarction in such a fulminant case. The other nine cases improved following cervical sympathectomy, whereas other therapeutic efforts such as osmotherapy, low molecular dextran solution, vasodilator or stellate ganglion block had failed to have effects. Aphasia, motor palsy, or disturbance of consciousness diminished between six hours and seven days following the cervical sympathectomy. The angiographic evidence of the occurrence of spasmolysis is shown in Table 1. Angiographic visibility of the thalamic perforating branches as well as vasospasm on the carotid fork seemed to correlate significantly with cerebral infarction disorders.

\section{Discussion}

The existence of cerebral vasospasm has only recently been recognized, based on angiographic evidence or under direct visual evidence of craniotomy. $1,4-6,8,10,12,14-16$, $18-20,23,30,31,34,41,42,47,48,51,52)$ Not much is known of its fundamental mechanism, neurogenic participation, incidence, or so-called spasmogenic substance. ${ }^{7,19,20,47)}$ The search for a spasmolytic agent looks hopeful but it seems still a long way from clinical use. ${ }^{29)}$

The therapeutic significance of cervical sympathectomy for cerebral ischemic disorders is equivocal. $2,7,12,24-28,32,33,39,43,51)$ Although, cervical sympathectomy was introduced as early as in $1952^{24)}$ its application seems to have been limited to brain damage due to a certain organic vascular lesions, such as thrombosis or embolism. ${ }^{2,24,28,32,33 \text { ) }}$

We feel neurogenic implication of this should be emphasized by both physiological study $^{3,9,21,22,39,40,49)}$ and recent electronmicroscopic study of innervation of the cerebral arteries. $^{36,38 \text { ) }}$

In accordance with the view that the internal carotid area is innervated mainly by the superior cervical sympathetic nerve ${ }^{17,37.49)}$ and that stimulation of this nerve results in cerebral vasoconstriction, ${ }^{21,26,511}$ we attempted therapeutic cervical sympathectomy in severe clinical cases with infarction following cerebral vasospasm. According to previous papers, cervical sympathectomy does not show blood flow increase in normal cerebral arteries, but this may be achieved in spastic vessels as in subarachnoid hemorrhage.

Prophylactic cervical sympathectomy in normal state may not be performed as a precaution against vasospasm because this may settle so-called "denervation hypersensitivity"11,511 and may result in vasospasm as seen in Case 7 .

This technique is still in a preliminary stage and should be proven further in a large series. It is our opinion that cervical sympathectomy is therapeutically valuable in some cases if done immediately after manifestation of cerebral infarction due to vasospasm and before cerebral disorder progresses to irreversible damage.

\section{References}

1) Corday, E., Rothenberg, S. F, and Irving, D. W.: Cerebral angiospasm. A case of the cerebral stroke. Am. I. Cardiol. $11: 66-71,1963$.

2) De Sousa Pereira, A. S.: Surgical treatment of internal carotid thrombosis. Ann. Surg. 141: 218-233, 1955.

3) Dollison, J. R., Bloor, B. M., Figueroa, A. F. Jr., and Loar, C. R.: The effects of cervical sympathetic stimulation on cerebrovascular hemodynamics. Surg. Forum. 20: 416-417, 1969.

4) Dukes, H. T. and Vieth, R. G.: Cerebral arteriography during migraine prodrome and headache. Neurology (Mineap) 14:636-639, 1964.

5) Echlin, F. A.: Vasospasm and focal cerebral ischemia. An experimental study. Arch. Neurol. Psychiat. 47: 77-96, 1942.

6) Echlin, F. A.: Spasm of basilar and vertebral arteries caused by experimental subarachnoid hemorrhage. J. Neurosurg. 23: 1-11, 1965.

7) Echlin, F. A.: Current concepts in the etiology and treatment of vasospasm. Clin. Neurosurg. 15: 133-166, 1968.

8) Ecker, A. and Riemenschneider, P. A.: Arteriographic demonstration of spasm of the intracranial arteries with special reference to saccular aneurisms. J. Neurosurg. 8: 660-667, 1951. 
9) Fang, H. C. H.: Cerebral arterial innervations in man. Arch. Neurol. (Chicago) 4: 651-656, 1961.

10) Forbes, H. S. and Cobb, S. Vasomotor control of cerebral vessels. Res. Publ. Ass. Res. Nerv. Ment. Dise. 18: 201-217, 1938.

11) Forbes, H. S.: Regulation of the cerebral vessels. New aspects. AMA Arch. Neurol. Psychiat. 80: 689-696, 1958.

12) Gurdjian, E. S. and Thomas, L. M.: Cerebral vasospasm. Surg. Gynec. and Obst. 129:931-948, 1969.

13) Harmel, M. H., Hafkenschiel, J. H., Austin, G. M., Crumpton, C. W., and Kety, S. S.: The effect of bilateral stellate ganglion block on the cerebral circulation in normotensive and hypertensive patients. J. Clin. Invest. 28: 415-418, 1949.

14) Hawkes, C. D. and Ogle, W. S. : Vasospasm with subarachnoid hemorrhage from intracranial aneurysm. Arch. Surg. 90: 404 409, 1965.

15) Herrmann, E. and Pia, H. W.: Der cerebrale Arteriospasmus. Kasuistischer und radiologischer Beitrag zum Frage nach der Existenz von Spasmen der Hirnarterien und ihrer Bedeutung für die Genese der ischämischen Insults. Deutsch. $Z$. Nervenhkd. 185: 381-392, 1963.

16) Heyck, H.: Zum Begriff des Angiospastischen Hirninsults. Internist. 4: 49-55, 1963.

17) Iwayama, T.: Ultrastructural change in the nerve innervating the cerebral artery after sympathectomy. $Z$. Zellforsch. 109: 465-480, 1970.

18) Kapp, J., Mahaley, M. S. Jr., and Odom, G. L.: Ccrebral arterial spasm. Part 1: Evaluation of experimental variables affecting the diameter of the exposed basilar artery. J. Neurosurg. 29: 331-338, 1968.

19) Kapp, J., Mahaley, M. S. Jr., and Odom, G. L.: Cerebral arterial spasm. Part 2: Experimental evaluation of mechanical and humoral factors in pathogenesis. J. Neurosurg. 29: 339-349, 1968.

20) Kapp, J., Mahaley, M. S. Jr., and Odom, G. L. : Cerebral arterial spasm. Part 3: Partial purification and characterization of spasmogenic substance in feline platelets. J. Neurosurg. $29: 350-360$, 1968.

21) Kobayashi, S., Waltz, A. G., and Rhoton, A. L.: Effects of stimulation of cervical sympathetic nerves on cortical blood flow and vascular reactivity. Neurology (Mineap) 21: 297-302, 1971.

22) Krog, J.: Autonomic nervous control of the cerebral blood flow in man. J. Oslo City Hosp. 14: 25-33, 1964.

23) Lende, R. A.: Local spasm in cerebral arteries. J. Neurosurg. 17: 90-103, 1960.

24) Leriche, R.: Treatment of embolism and thrombosis of the cerebral vessels. Brit. Med. J. 1:231-235, 1952.

25) Lindén, L. : The effect of stellate ganglion block on cerebral circulation in cerebrovascular accidents. Acta. Med. Scandinav. Suppl. 301: 1-110, 1955.

26) Little, J. M., Cordell, A. R., and Conrad, E. A.: Chronic carotid sinus compression in dogs. A study of hemodynamic changes with and without sinus denervation. Circul. Res. 11: 161-169, 1962.

27) Ludwigs, N. and Schneider, M. : Über den Einfluss des Hals sympathicus auf die Gehirndurchblutung Pflüg. Arch. ges. Physiol. 259: 43-55, 1954.

28) Murakami, J, and Ando, E.: Sympathectomy and its indication in the treatment of the cerebral arteriosclerotic vascular diseases. Arch. Jap. Chir. 24: 125-131, 1955.

29) Pelofsky, S., Jacobson, E. D., and Fisher, R. G. : Effects of prostaglandin $E_{1}$ on experimental cerebral vasospasm. J. Neurosurg. 36: 634-639, 1972.

30) Pickerling, G. W., Camb, M. B., and Ghent, M. D.: Vascular spasm. Lancet. 261: 845-850, 1951 .

31) Pool, J. L.: Cerebral vasospasm. New Engl. J. Med. 259: 1259-1264, 1958.

32) Poppen, J. L. and Fager, A. C. Jr.: Cervical sympathectomy in the treatment of cerebral vascular disorders. Lahey Clin. Bull. 8: 142-148, 1952.

33) Poppen, J. L. and Baird, W. C.: Nontraumatic thrombosis of the internal carotid artery. A report of twenty-five cases. Surg. Clin. North Amer. 32: $781-785,1952$.

34) Rothenberg, S. F. and Corday, E. : Etiology of the transient cerebral stroke. JAMA 164: 2005-2008, 1957.

35) Ruch, T. C. and Fulton, J. F.: Medical physiology and biophysics. Philadelphia, WB Saunders, 1960.

36) Sato, S.: An electron microscopic study on the innervation of the intracranial artery of the rat. Amer. J. Anat. 118: 873-890, 1966.

37) Sato, S., Sato, T., Endo, S., and Suzuki, J.: Neurogenic participation in cerebral angiospasm. Electronmicroscopic study. Proc. 5th Conf, on Specific Topics in Neurosurgery (Tokyo), 117-130, 1972.

38) Sato, S. and Suzuki, J.: Anatomical mapping of the cerebral nervi vasorum in the human brain. J. Neurosurg. 43: 559-568, 1975.

39) Shackelford, R. T. and Hegedus, S. A.: Bilateral superior cervical sympathectomy. Arch. Surg. 82: 308-313, 1961.

40) Schmidt, C. F.: The intrinsic regulation of the circulation in the hypothalamus of the cat. $\mathrm{Am}$. J. Physiol. 110: 137-152, 1934

41) Schneck, S. A. and Kricheff, I. I.: Intracranial aneurysm rupture, vasospasm, and infarction. Arch. Neurol. (Chicago) 11:668-680, 1964.

42) Sedzimer, C. B. : Head injury as a cause of internal carotid thrombosis. J. Neurol. Neurosurg. Psychiat. 18: 293-296, 1955.

43) Shenkin, H. A., Cabieses, F., and Van den Noordt, G.: The effect of bilateral stellate ganglionectomy upon the cerebral circulation of man. J. Clin. Invest. 30: 90-93, 1951 .

44) Simeone, F. A., Ryan, K. G., and Cotter, J. R.: Prolonged experimental cerebral vasospasm. $J$. Neurosurg. 29: 357-366, 1968.

45) Suzuki, J., Takaku, A., and Kodama, N. : Prognostic correlation with the cerebral vasospasm and 
the direct operation for the intracranial aneurysm. Jap. J. Surg. (Tokyo) 1: 210-215, 1972.

46) Suzuki, J. and Yoshimoto, T.: Early operation of the ruptured intracranial aneurysm. Jap. J. Surg. (Tokyo) 3: 149-156, 1973.

47) Suzuki, S.: Experimental study of cerebral vasospasm. Vasospasm of the circle of Willis. Brain Nerve. (Tokyo) 22: 393-403, 1970.

48) Tanaka, T.: Cerebral angiospasm. An experimental study of the intracranial vertebrobasilar system. Adv. Neurol. Sci. (Tokyo) 12: 554-565, 1968.

49) Terasawa, F.: The experimental study of the nervous control of the cerebral circulation. 1 . The influences of the stimulation of the cervical sympathetic nerve on the blood flow in the internal and external carotid arteries. II. The influences of the stimulation of the proximal end of the cut cervical vagal nerve on the blood flow in the internal and external carotid arteries before and after cervical sympathectomy. Jap. Circ. J. 25 : 1123-1144, 1961

50) Wells, C. E.: The cerebral circulation. The clinical significance of current concepts. Arch. Neurol. (Chicago) 3: 319-331, 1960.

51) White, J. C.: Nervous control of the cerebral vascular system. Clin. Neurosurg. 9: 67-87, 1963.

52) Wilkins, R. G., Alexander, J. A., and Odom, G. L. : Intracranial arterial spasm. A clinical analysis. J. Neurosurg. 29: 121-134, 1968.

53) Zita, G., Hawliczek, F., and Kittinger, G.: Zerebrale Durchblutungsmessung mit Hilfe von $I^{131}$-markiertem Humanserumalbumin vor und nach Ganglion stellatum-Blockaade. Z. Laryng. Rhinol. Otol. 43: 167-176, 1964. 